\title{
ANALISIS EFFICIENT MARKET HYPOTHESIS PADA BURSA EFEK INDONESIA TERHADAP PASAR SAHAM ASEAN
}

\author{
Astriyana Prima Kartika1), Jubaedah 2), Fitri Yetti ${ }^{3)}$
}

1)23) Dosen Fakultas Ekonomi Universitas Pembangunan Nasional "Veteran" Jakarta

E-mail:jubaedah_nawir@yahoo.co.id

\begin{abstract}
Abstraksi
Penelitian ini bertujuan untuk menganalisis kinerja Bursa Efek Indonesia terhadap pasar saham ASEAN selama periode 2012-2016. Teknik penentuan sampel menggunakan metode purposive sampling dan menghasilkan 6 negara sebagai sampel yaitu Indonesia, Singapura, Malaysia, Vietnam dan Filipina. Pengujian hipotesis dalam penelitian ini menggunakan Analisis Deskriptif Statistik, Uji Run dan Kolomogorov Smirnov. Hasil pengujian menunjukkan bahwa: (1) Bursa Efek Indonesia memiliki peringkat efisien tertinggi di pasar saham ASEAN (2) Bursa Efek ASEAN berpengaruh terhadap Bursa Efek Indonesia. (3) Bursa Efek Indonesia memiliki pola return saham yang berfluktuasi secara normal di pasar saham ASEAN.
\end{abstract}

Kata kunci: Hipotesis Pasar Efisien, Bursa Efek, Return Saham

\begin{abstract}
This research aims to analyze the performance of Indonesia Stock Exchange to ASEAN stock market during period 2012-2016. The technique of determining the sample using purposive sampling method and 6 countries as sample are Indonesia, Singapore, Malaysia, Vietnam and Philippines. Hypothesis testing in this study using Descriptive Statistics Analysis, Test Run and Kolomogorov Smirnov. The results show that: (1) Indonesia Stock Exchange has the highest efficient rating in ASEAN stock market (2) ASEAN Stock Exchange effect on Indonesia Stock Exchange. (3) The Indonesia Stock Exchange has a stock return pattern that fluctuates normally in the ASEAN stock market.
\end{abstract}

Keywords : efficient market hypothesis, stock market, stock return 


\section{PENDAHULUAN}

\section{Latar Belakang}

Perkembangan pasar saham di dunia saat ini sangatlah pesat, karena didukung oleh kemajuan teknologi sehingga memudahkan setiap investor dalam melakukan suatu transaksi. Bursa efek merupakan barometer untuk melihat kemajuan suatu negara. Kawasan ASIA persaingan bursa efek sudah terbagi menjadi beberapa regional seperti Asia Timur (Jepang, China, Korea dan lain - lain), Asia Barat (Uni Emirat Arab, Arab Saudi, Qatar dan lain - lain), Asia Tengah (India, Nepal dan lain - lain) dan terakhir adalah Asia Tenggara (Indonesia, Malaysia, Singapura, Vietnam, Thailand, Filipina dan lain - lain).

Penelitian ini menganalisis efisiensi pasar pada Bursa Efek Indonesia Terhadap Pasar Saham ASEAN Periode 2012 - 2016. Penelitian ini di dukung oleh beberapa penelitian terdahulu yaitu Yuan dan Gupta (2014), Stakic et. al. (2015), Nassar (2016), Singh et. al. (2016), Maheswarant dan Sahik (2016). Berikut ini adalah data 10 saham terbesar dari sisi market cap, yang terdaftar di bursa-bursa saham Singapura, Indonesia, Malaysia, dan Thailand:

Tabel 1. Market cap ASEAN

\begin{tabular}{lcc}
\hline Companies & Closing price & Market cap \\
\hline \multicolumn{1}{l}{ Singapore (SGX) } & & \\
\hline SingTel & 3.56 & 40.80 \\
\hline Jardine Matheson & 53.23 & 37.90 \\
\hline Jardine Strategic & 27.92 & 30.80 \\
\hline DBS Group & 13.02 & 23.30 \\
\hline OCBC & 7.46 & 22.00 \\
\hline UOB & 17.56 & 20.20 \\
\hline Hongkong Land & 5.62 & 13.20 \\
\hline Wilmar International & 2.91 & 13.20 \\
\hline IHH Healthcare & 2.11 & 12.40 \\
\hline Thai Beverage & 0.68 & 12.10 \\
\hline Indonesia (IDX) & & 36.50 \\
\hline HM Sampoerna & $105,700.00$ & 24.60 \\
\hline Telkom Indonesia & $3,285.00$ & 24.10 \\
\hline BCA & $13,275.00$ & 23.30 \\
\hline Unilever Indonesia & $41,100.00$ & 21.40 \\
\hline BRI & $11,800.00$ & 20.50 \\
\hline Astra International & $6,825.00$ & 16.70 \\
\hline Bank Mandiri & $9,725.00$ & 8.70 \\
\hline Gudang Garam & $60,700.00$ & 7.20 \\
\hline BNI & $5,275.00$ & 6.40 \\
\hline Indofood CBP & $14,725.00$ & \\
\hline \multicolumn{1}{c}{ Malaysia (Bursa Malaysia) } & \\
\hline & & \\
\hline
\end{tabular}


Analisis Efficient Market Hypotesis Pada Bursa Efek Indonesia ...

\begin{tabular}{|c|c|c|}
\hline Maybank & 8.51 & 20.00 \\
\hline Public Bank & 18.50 & 17.20 \\
\hline Petronas Chemicals & 6.90 & 13.30 \\
\hline IHH Healthcare & 6.49 & 12.90 \\
\hline Axiata Group & 5.60 & 11.90 \\
\hline Maxis & 6.06 & 11.00 \\
\hline Petronas Gas & 22.24 & 10.60 \\
\hline DiGi.com & 4.85 & 9.10 \\
\hline CIMB Group & 4.20 & 8.60 \\
\hline IOI Corporation & 4.67 & 7.10 \\
\hline \multicolumn{3}{|c|}{ Thailand (SET) } \\
\hline PTT & 230.00 & 18.40 \\
\hline Siam Cement & 426.00 & 14.40 \\
\hline Advanced Info Service & 166.50 & 13.90 \\
\hline Siam Commercial Bank & 130.00 & 12.40 \\
\hline Kasikornbank & 161.00 & 10.80 \\
\hline CP ALL & 40.30 & 10.20 \\
\hline Bangkok Bank & 148.00 & 7.90 \\
\hline Krung Thai Bank & 17.20 & 6.70 \\
\hline PTT Global Chemical & 51.50 & 6.50 \\
\hline Bank of Ayudhya & 30.30 & 6.20 \\
\hline
\end{tabular}

Terdapat perusahaan yang memiliki dual listing atau terdaftar dalam dua bursa saham di dua negara yaitu perusahaan IHH Healthcare yang berdiri di Malaysia, meskipun terdaftar di bursa saham Malaysia dan bursa saham Singapura. Selain itu terdapat juga perusahaan yang berdiri di negara Thailand tetapi terdaftar di negara Singapura yaitu perusahaan Thai Beverage. Dari data tabel diatas dapat terlihat saham dengan market cap terbesar berada di negara Singapura yaitu SingTel. Dan jika dari daftar diatas diambil lima belas saham terbesar dari sisi market cap, maka sebagai berikut hasilnya (market cap dalam milyar US Dollar):

Tabel 2. Perusahaan dengan Market Tinggi

\begin{tabular}{llc}
\hline Companies & Country & Market cap \\
\hline SingTel & Singapore & 40.84 \\
\hline Jardine Matheson & Singapore & 37.89 \\
\hline HM Sampoerna & Indonesia & 36.52 \\
\hline Jardine Strategic & Singapore & 30.79 \\
\hline Telkom Indonesia & Indonesia & 24.57 \\
\hline BCA & Indonesia & 24.05 \\
\hline Unilever Indonesia & Indonesia & 23.31 \\
\hline DBS Group & Singapore & 23.29 \\
\hline OCBC & Singapore & 21.96 \\
\hline BRI & Indonesia & 21.38 \\
\hline Astra International & Indonesia & 20.49 \\
\hline
\end{tabular}


Soedirman Accounting Review. Volume 02 Nomor 02 Tahun 2017, 128 - 145

\begin{tabular}{lcc}
\hline UOB & Singapore & 20.20 \\
\hline Maybank & Malaysia & 20.02 \\
\hline PTT & Thailand & 18.44 \\
\hline Public Bank Bhd & Malaysia & 17.21 \\
\hline
\end{tabular}

Sumber: www.investing.com

Dari data tabel 2 terlihat bahwa posisi pasar modal Indonesia (IDX) berada pada posisi yang lebih baik dibanding posisi pasar modal di Malaysia dan Thailand, tetapi masih kalah dari Singapura (SGX). Indonesia memiliki GDP sebesar USD 889 milyar, maka dapat dikatakan Indonesia merupakan negara yang memiliki perekonomian terbesar di Asia Tenggara, jauh lebih besar dibanding Singapura yang hanya memiliki GDP USD 308 milyar. Namun dari sisi nilai saham yang listing di pasar modal per tanggal 12 Februari 2016. Saham - saham yang terdaftar di Indonesia rata - rata memiliki market cap total sebesar 5,005 triliyun rupiah atau setara dengan USD 371 milyar. Sementara saham - saham yang terdaftar di Singapore per akhir Januari 2016 tercatat memiliki market cap sebesar SGD 855 milyar, atau setara USD 612 milyar.

Dari trend yang terjadi maka dapat disimpulkan bahwa IDX memiliki peluang untuk mengambil alih posisi SGX sebagai bursa saham terbesar di Asia Tenggara. Ketika perusahaan Singapura berinvestasi atau membuka kantor cabang di luar Singapura, maka aktivitas operasional perusahaan tersebut akan dibatasi oleh peraturan - peraturan yang berlaku di negara asal tempat perusahaan tersebut mendirikan kantor cabang. Dan karena faktor tersebut perusahaan yang membuka kantor cabang di negara lain akan sulit untuk bisa menjadi perusahaan terbesar di negara tempat asal berdirinya.

Perusahaan di Indonesia memiliki banyak ruang untuk berkembang di negaranya sendiri, dan setelah mereka mampu untuk berkembang peluang bagi IDX untuk melakukan expansi sangat besar. Dari hal tersebut akan membuat IDX lebih mudah untuk tumbuh agar bisa menjadi lebih besar dan juga menarik minat para investor melakukan investasi di Indonesia. Pemerintah Indonesia dalam hal ini adalah Bursa Efek Indonesia (BEI) bisa mencontoh pemerintah Singapura dalam membuat kebijakan - kebijakan membuat pasar saham Indonesia berkembang, seperti: mendorong perusahaan-perusahaan asing untuk listing di BEI atau dual listing dengan menawarkan kemudahan-kemudahan tertentu. Jika ini sulit dilakukan, maka minimal perusahaan-perusahaan Indonesia yang listing di Singapura bisa diarahkan untuk juga listing di BEI, membuka peluang masuknya investasi asing dimana mereka bisa membeli sahamsaham dari perusahaan asing tersebut, menciptakan dan mengembangkan produk-produk investasi/trading diluar saham dan obligasi, seperti indeks futures, exchange traded funds, real estate investment trust (REIT), business trust, structured warrants dan lain - lain.

Diharapkan dengan kebijakan tersebut pasar saham Indonesia dapat berkembang. Namun kebijakan tersebut termasuk kebijakan yang menganut paham liberalisme dan juga 
dapat menimbulkan efek persaingan bagi investor/perusahaan lokal akan sulit berkembang. Tetapi di beberapa negara financial center seperti Singapura, Hongkong, dan Swiss telah menerapkan kebijakan tersebut dan berhasil membuat pasar modal dan juga perekonomiannya berkembang pesat secara keseluruhan.

\section{Identifikasi Masalah}

Berdasarakan latar belakang yang telah diuraikan, terdapat fenomena yang membahas efisiensi pasar saham di ASEAN yang mana didalamnya terdapat pasar - pasar saham kuat seperti BEI (Bursa Efek Indonesia), STTF (Bursa Saham Singapura), KLCI (Bursa Saham Malaysia) , PSEi (Bursa Saham Philippina), SET Index (Bursa Saham Thailand), dan FTSE (Bursa Saham Vietnam). Pada penelitian ini terdapat beberapa masalah yang akan dibahas yaitu, kinerja Bursa Efek Indonesia dalam peringkat efisien market di ASEAN. Bursa Saham ASEAN mempengaruhi Bursa Efek Indonesia terutama pada pola return saham random terhadap pasar saham di masing - masing negara di ASEAN.

\section{Tujuan Penelitian}

Penelitian ini memiliki tujuan untuk mengetahui performance peringkat efisien market Bursa Efek Indonesia di ASEAN, mengetahui pengaruh Bursa Saham ASEAN terhadap Bursa Efek Indonesia, mengetahui kategori efisiensi pasar Bursa Efek Indonesia pada pasar saham ASEAN, mengetahui pola Return saham random di pasar saham ASEAN..

\section{Kegunaan Penelitian}

Hasil penelitian ini diharapkan akan mampu mengembangkan model alternatif yang dapat dijadikan rujukan bagi penelitian lebih lanjut yang berhubungan dengan efisiensi bursa efek Indonesia terhadap bursa efek negara-nagara ASEAN dan penelitian ini diharapkan dapat bermanfaat bagi pihak-pihak yang membutuhkan sebagai informasi bagi para pelaku pasar modal di Indonesia tentang kinerja bursa efek Indonesia serta informasi bagi investor dalam keputusan investasi pada perusahaan yang dual listing.

\section{Tinjauan Literatur Dan Pengembangan Hipotesis}

\section{Efficient Market Hypotesis Theory}

Teori yang menjelaskan tentang tingkat efisiensi pasar saham di suatu negara. Tingkat efisien pasar dapat di gambarkan dan di jelaskan melalui informasi - informasi yang di berikan oleh suatu perusahaan mengenai kekuatan serta kelemahannya. Efisiensi pasar itu sendiri dibagi menjadi tiga yaitu pasar efisien lemah, pasar efisien semi kuat, dan terakhir pasar efisiensi kuat. Fama (1970) mendefinisikan pasar efisien adalah "suatu pasar sekuritas dikatakan efisien jika harga - harga sekurtas "mencerminkan secara penuh 'informasi yang tersedia. Bentuk pasar efisien ada tiga yaitu: 


\section{Weak Form Hypothesis}

Merupakan suatu keadaan dimana harga saham menggambarkan semua informasi yang ada pada catatan harga di waktu lalu. Bila ditingkat efisiensi bentuk lemah ini tercapai, pada kondisi pasar ini maka seorang manajer akan sangat sulit dan bahkan tidak mungkin bisa mendapatkan keuntungan diatas normal return (abnormal return), sehingga sangat sulit memprediksi arah perubahan harga periode yang akan datang.

\section{Semi Strong Form Hypothesis}

Merupakan suatu keadaan pasar dimana harga - harga bukan hanya mencerminkan harga - harga di waktu yang lalu, tetapi semua informasi yang dipublikasikan. Informasi yang di publikasi akan tergambarkan ke dalam harga saham secara cepat dan tidak bias. Investor tidak akan dapat memperoleh keuntungan di atas normal (abnormal return), dengan membeli saham atas dasar suatu publikasi.

Strong Form Hypothesis

Merupakan suatu kondisi pasar dimana semua informasi yang relevan yang tersedia tercermin dalam harga saham. Sehingga baik informasi yang telah dipublikasikan maupun yang belum dipublikasikan (private information) akan tercermin dalam harga saham. Dalam keadaan seperti ini tidak seorang investor pun dapat memperoleh abnormal return (excess return) dengan menggunakan informasi apapun.

\section{Pengujian Terhadap Hipotesis Pasar Efisien}

Pengujian hipotesis pasar efisien menurut Tandelilin (2010) menyatakan bahwa hipotesis pasar efisien dapat di uji dengan melakukan pengujian sebagai berikut:

\section{Pengujian Weak Form Hypothesis}

Pada pengujian ini kita mempelajari pola return, menggunakan data return di masa yang lalu, mempelajari hubungan return dengan karakteristik perusahaan.

\section{Pengujian Semi Strong Form Hypothesis}

Pada pengujian ini seorang investor mengamati dan menganalisis dampak dari pengumuman informasi terhadap harga sekuritas yang sering disebut event studies. Pada pengujian event studies terdapat beberapa metodologi yang digunakan sebagai berikut: mengumpulkan sampel, mengidentifikasi hari pengumuman atau event, menentukan periode analisis, menghitung return aktual masing - masing sampel setiap hari selama periode pengamatan, menghitung return tak normal, menghitung rata - rata return tak normal semua sampel setiap hari, terkadang return tak normal harian tersebut digabungkan untuk menghitung return tak normal komulatif selama periode tertentu, mempelajari dan mendiskusikan hasil yang diperoleh. 
Analisis Efficient Market Hypotesis Pada Bursa Efek Indonesia ...

\section{Pengujian Strong Form Hypothesis}

Ketika kondisi pasar dikatakan kuat atau strong form hypothesis maka seorang investor akan melakukan pengujian terhadap pihak insider perusahaan dan kelompok investor tertentu yang dianggap mempunyai akses informasi lebih baik, dapat memperoleh return tak normal lebih tinggi dibandingkan dengan return pasar umumnya.

\section{Efficient Market Hypothesis Pasar Saham ASEAN}

Efficient market hypothesis pasar saham merupakan tingkat efisien dari pasar saham yang dapat tergambarkan oleh informasi - informasi yang ada selama periode waktu tertentu. Pada penelitian ini tingkat efficient market hypothesis dapat terlhat dari histori data penjualan pada tarnsaksi closing price pasar saham ASEAN. Asumsi ini diperkuat dari penelitian yang telah dilakukan oleh peneliti sebelumnya seperti Aumeboonsuke (2012) “Weak Form Efficiency of Six Equity Exchange in ASEAN", Salim et. al. (2013) "Testing the Weak Form Efficiency of the Stock Market: Pakistan as an Emerging Economy", Gupta \& Guidi (2013) "Market Efficiency in the ASEAN Region: Evidence from Multivariate and Cointegration Test”, Dyakova \& Smith (2014) “ African Stock Markets: Efficiency and Relative Predict Ability", Yuan \& Gupta (2014) "Chinese Lunar New Year Effect in Asia Stock Markets, 1999 - 2012”, Stakic et. al. (2015) “ The Efficiency of The Stock Market In Serbia", Nassar (2016) "The Day of The Week Effect Of Stock Return: Empirical Evidence From Five Selected Arab Countries", Singh et. al. (2016) "Testing the Weak form of Efficient Market Hypothesis In Carbon Efficient Stocks Indics Along With Their Bencmark Indices In Select Countries”, Maheswarant dan Sahik (2016)“Random Walk in Emerging ASIAN Stock Markets".

Dalam penelitian ini dapat dikembangkan hipotesis tentang tingkat efisiensi pasar saham Indonesia pada pasar saham ASEAN, dengan hipotesis sebagai berikut:

\section{Peringkat Efisien Pasar Saham Bursa Efek Indonesia pada pasar saham ASEAN}

Peringkat efisien pasar saham ASEAN dapat di lihat berdasarkan tingkat market cap atau juga dapat terlihat melalui return pasarnya. Hal ini didukung penelitian yang dilakukan oleh Singh, Leepsa, Kushwaha (2016). Hasil penelitian tersebut adalah didapatkan bahwa dari 4 negara hanya Jepang yang memiliki tingkat return yang tidak normal tiap bulannya dikarenakan dampak Tsunami yang melanda Jepang pada tahun 2011. Berdasarkan teori dan hasil penelitian terdahulu dapat dirumuskan hipotesis pertama (H1) : Bursa Efek Indonesia memiliki peringkat efisien market yang tinggi di ASEAN.

\section{Pengaruh Bursa Saham ASEAN terhadap Bursa Efek Indonesia}

Pengaruh atau tidaknya suatu bursa terhadap bursa lain dapat terlihat dari faktor IPOLEKSOSBUD di suatu negara. Pernyataan tersebut didukung penelitian oleh Nassar (2016). Pada Palestine Stock, stock return pada hari Minggu mempunyai return yang rendah dan pada 
hari Selasa baru mengalami kenaikan. Mesir dan Qatar Stock mempunyai tingkat return yang baik selama satu minggu tetapi mengalami penurunan pada hari senin. Jordania dan Bahrain pada hari Minggu, Senin, dan Selasa mengalami penurunan dan 4 hari selanjutnya mengalami kenaikan return. Berdasarkan teori dan hasil penelitian terdahulu dapat dirumuskan hipotesis kedua (H2) : Bursa Saham ASEAN berpengaruh terhadap Bursa Efek Indonesia.

\section{Bursa Efek Indonesia Memiliki Kategori Efisien Pasar pada Pasar Saham ASEAN}

Bursa Efek Indonesia memiliki peringkat efisien pasar pada pasar saham ASEAN, hal itu didukung penelitian oleh Stakic, Jovancai, Kapor (2015). Berdasarkan hasil penelitian tersebut dapat dijelaskan bahwa terdapat 2 periode yang menunjukan perbedaan yang sangat kontras, pada periode 2007 - 2009 terjadi pertumbuhan return yang sangat rendah yang mana hanya mengalami kenaikan sebesar 347.46 point sedangkan pada periode 2010 - 2013 mengalami kenaikan yang cukup tinggi. Hal tersebut dikarenakan adanya gejolak perekonomian dunia. Berdasarkan teori dan hasil penelitian terdahulu dapat dirumuskan hipotesis ketiga (H3): Bursa Efek Indonesia memiliki kategori efisien pasar pada pasar saham ASEAN.

Pasar Saham ASEAN Memiliki Pola Return Saham Random terhadap Pasar Saham di Masing - masing negara di ASEAN

Pasar saham ASEAN memiliki pola return saham random terhadap pasar saham di masing - masing negara, hal tersebut didukung penelitian oleh Yuan, Gupta (2014). Penelitian ini dilakukan pada saat tahun baru China di tujuh pasar saham ASIA, yaitu China, Hong kong, Jepang, Malaysia, Singapura, Korea Selatan dan Taiwan. Dari penelitian tersebut dapat di temukan bahwa efek tahun baru China atau imlek mengakibatkan pasar saham di ketujuh negara ASIA tersebut tidak selalu infisiensi pasarnya tinggi dikarenakan terdapat hubungan yang positif antara risiko dengan return sahamnya. Selanjutnya risiko bersyarat yang di sebabkan krisis di ASIA pada tahun 1997 menyebabkan China menjadi lebih baik dibandingkan dengan enam negara lainnya. Pasar saham China lebih di dominasi oleh investor ritel yang mana mereka lebih menginginkan keuntungan jangka pendek dan tidak setuju dengan keputusan investasi jangka panjang. Berdasarkan teori dan hasil penelitian terdahulu dapat dirumuskan hipotesis keempat (H4) : Pasar saham ASEAN memiliki pola return saham random terhadap pasar saham di masing -masing negara di ASEAN.

\section{Metode Penelitian}

\section{Return Saham Bursa Efek Indonesia}

Return saham pada Bursa Efek Indonesia (BEI) merupakan suatu tingkat return saham yang didapatkan dari kegiatan perdagangan saham pada BEI. BEI mempunyai beberapa indek sektoral, yaitu : IHSG, Indeks Individual, Indeks LQ45, Index IDX30, Indeks Kompas100, Indeks Sektoral, Jakarta Islamic Indeks, Indeks Bursa Syariah Indonesia, Indeks Bisnis-27, Indeks 
Analisis Efficient Market Hypotesis Pada Bursa Efek Indonesia ...

Pefindo25, Indeks SRI-KEHATI, Indeks Sminfra18, dan Indeks Papan Utama dan Papan Pengembangan.

\section{Return Saham Singapore Exchange}

Return saham pada Singapore Exchange (SGX) merupakan suatu tingkat return saham yang didapatkan dari kegiatan perdagangan saham pada Singapore Exchange. Bursa ini memperdagangkan sekuritas seperti obligasi pemerintah dan derivatif (opsi saham). Indeks pasar saham utama SGX adalah Indeks Straits Times (Straits Times Index, STI).

\section{Return Saham Bursa Saham Kuala Lumpur}

Return saham pada Bursa Saham Kuala Lumpur (Kuala Lumpur Stock Exchange) merupakan suatu tingkat Return saham yang didapatkan dari kegiatan perdagangan saham pada Bursa Saham Kuala Lumpur (Kuala Lumpur Stock Exchange). Indeks pasar saham pertama untuk Bursa Malaysia adalah Indeks Komposit Kuala Lumpur (KLCI). Namun, pada Juni 2006, satu seri indeks baru dikembangkan secara bersama oleh Bursa Malaysia dan FTSE berkumpul telah diperkenalkan.

\section{Return Saham Stock Exchange of Thailand}

Return saham pada Stock Exchange of Thailand (SET) adalah suatu tingkat Return saham yang didapatkan dari kegiatan perdagangan saham pada Stock Exchange of Thailand (SET). Bursa Efek Thailand telah 584 perusahaan yang terdaftar dengan gabungan kapitalisasi pasar sebesar BT\$11.496 miliar. Indeks pasar saham SET adalah Indeks SET, Indeks Set50, dan Indeks SET100.

\section{Return Saham Hanoi Securities Trading Center}

Return saham pada Hanoi Securities Trading Center (Hanoi STC) merupakan suatu tingkat Return saham yang didapatkan dari kegiatan perdagangan saham pada Hanoi Securities Trading Center (Hanoi STC). Indeks pada Hanoi Securities Trading Center (Hanoi STC) adalah Vietnam Ho Chi Minh Stock Index.

\section{Return Saham The Philippine Stock Exchange}

Return saham pada The Philippine Stock Exchange (PSE) merupakan suatu tingkat Return saham yang didapatkan dari kegiatan perdagangan saham pada The Philippine Stock Exchange (PSE) yang dapat dilihat dari nilai closing price bursa saham dari perusahaan yang telah listing. Nama saham yang beroperasi di The Philippine Stock Exchange (PSE) adalah PSE Composite Index.

\section{Pengukuran Variabel}

Return Saham di Bursa Saham ASEAN yang diukur dengan Run Test $=\mathrm{Ri}=\mathrm{LN}(\mathrm{Pt} / \mathrm{Pt}-1)$ 


\section{Populasi dan Sampel}

Populasi merupakan objek atau subjek yang berbeda pada suatu wilayah dan memahami syarat-syarat tertentu yang berkaitan dengan masalah penelitian. Populasi yang akan menjadi objek penelitian ini adalah : Pasar Saham ASEAN periode 2012 - 2016 yang terdiri 6 pasar saham utama yaitu Bursa Efek Indonesia, Singapoer Exchange, Kuala Lumpur Stock Exchange, Stock Exchange of Thailand, Hanoi Scurities Trading Center, The Philippine Stock Exchange.

Metode pengambilan sampel yang digunakan dalam penelitian ini adalah dengan menggunakan metode purposive sampling yaitu teknik penentuan sampel dengan pertimbangan tertentu. Dalam hal ini sampel dari penelitian ini didasari dengan kriteria sebagai berikut: merupakan bursa saham yang terdaftar di bursa saham ASEAN; merupakan bursa saham yang memiliki tingkat return saham yang tinggi di kawasan ASEAN; merupakan bursa saham yang memiliki peluang tinggi untuk menjadi bursa saham terbaik di ASEAN; merupakan bursa saham yang memiliki pola return yang berfluktuasi.

\section{Teknik Analisis}

Teknik analisis yang digunakan adalah sebagai berikut: (1) Statistik Deskriptif; (2) Run Test. Kolmogorov-Smirnov Test yang merupakan suatu pengujian atau sebuah tes goodness-of-fit, yaitu menguji kesesuaian antar distribusi serangkaian nilai sampel (skor yang di observasi) dengan distribusi teoritis tertentu.

\section{HASIL DAN PEMBAHASAN}

\section{Deskripsi Data Penelitian}

Data yang digunakan pada penelitian ini didasarkan pada closing price pada pasar saham dari 6 negara yang memiliki dan aktif dalam transaksi pasar saham di kawasan regional ASEAN periode 2012 - 2016. Pada penelitian ini menganalisis nilai dari return saham yang didapatkan dari nilai closing price yang telah di publikasi oleh masing - masing bursa dari setiap negara. Penelitian ini dilakukan pada pasar saham di kawasan regional ASEAN sehingga dapat menghasilkan peringkat negara yang memiliki Efficient Market Hypothesis tertinggi. Berikut ini merupakan tabel nilai closing price dari 6 negara yang memiliki dan aktif di bursa saham kawasan regional ASEAN.

\section{Analisis Statistik Deskritif}

Tabel 3. Statistik Deskriptif

\begin{tabular}{|c|c|c|c|c|c|c|}
\hline & BEI & KLCI & SGX & PSEi & SET & $\mathrm{VN}$ \\
\hline $\mathrm{N}$ Valid & 60 & 60 & 60 & 60 & 60 & 60 \\
\hline Missing & 0 & 0 & 0 & 0 & 0 & 0 \\
\hline Mean & $63,067,026.38$ & $7,348.629$ & 4.350 & $331,795.043$ & $48,040.952$ & $6,692,598.000$ \\
\hline
\end{tabular}

Sumber: diolah dari berbagai sumber 
Analisis Efficient Market Hypotesis Pada Bursa Efek Indonesia ...

\section{Bursa Efek Indonesia}

Pada bursa ini dapat dijelaskan bahwa memiliki kondisi harga saham yang cukup kuat dikarenakan memiliki nilai closing price yang berada di atas harga standar berjumlah 56,67\% sedangkan nilai yang berada dibawah harga closing price sebesar 43,33\% dari 60 sampel selama 5 periode yaitu tahun 2012 - 2017. Selama 5 tahun periode pengamatan dapat dijelaskan bahwa nilai closing price terendah terjadi sepanjang tahun 2012, hal itu disebabkan krisis global dunia yang mempengaruhi kondisi ekonomi di Indonesia sehingga Indonesia harus menjaga perekonomian pada sektor riil dan juga memperbaiki volume ekspor Indonesia yang cenderung menurun pada tahun sebelumnya. Selain itu pertumbuhan ekonomi di Indonesia pada tahun 2012 mengalami kenaikan sebesar 6,2\% dengan inflasi yang terkendali sebesar 4,3\%.

\section{Kuala Lumpur Stock Exchange}

Pada bursa Kuala Lumpur Stock Exchange terlihat bahwa 53,33\% nilai closing price berada di bawah harga standar selama 5 tahun terakhir sedangkan nilai yang diatas nilai normal hanya sebesar 46,67\%. Nilai tersebut diakibatkan oleh krisis yang sedang di hadapi Malaysia, seperti krisis politik atau dugaan korupsi Perdana Menteri Malaysia. Selain itu Produk Domestik Bruto Malaysia mengalami kenaikan menjadi 86\%, hal tersebut mengakibatkan nilai tukar ringgit Malaysia terhadap dollar Amerika melemah sebesar 40\% menjadi RM 4,34 per USD. Meskipun Malaysia sedang mengalami krisis pemerintah Malaysia yakin dan optimis bahwa perekonomian Malaysia dapat membaik pada tahun 2016. Pertumbuhan ekonomi Malaysia pada tahun 2016 sebesar 4,5\% yang lebih kecil dari pertumbuhan pada 2015 yaitu sebesar 5\%. Pertumbuhan ekonomi tersebut didukung oleh Malaysia sebagai negara eksportir terbesar kedua dalam sektor gas alam cair yang mengalami hambatan dikarenakan kasus dugaan korupsi yang melibatkan BUMN1 Malaysia.

\section{Singapore Exchange}

Singapore Exchange pada tahun 2012 sampai pertengahan 2015 mengalami penguatan nilai closing price dan menjadi salah satu tolak ukur bagi perekonomian di kawasan ASEAN dikarenakan nilai dollar Singapura terhadap dollar Amerika mengalami penguatan dari tahun 2012 sampai pertengahan tahun 2015 namun setelah bulan Juli 2015 Singapura mengalami penurunan nilai closing price. Sebenarnya ekonomi Singapura pada kuartal keempat mengalami pertumbuhan sebesar 1,8\%, dimana sektor manufaktur menyumbang sekitar seperlima dari total PDB, kontraksi 6,7\% pada kuartal keempat. Kontraksi tersebut disebabkan oleh penurunan produksi rekayasa transportasi dan elektronik. Untuk produk domestik bruto tiga bulan sampai akhir Desember naik 6,2\% secara musiman disesuaikan dan tahunan dibandingkan dengan kuartal sebelumnya. Untuk keseluruhan tahun 2015, perekonomian Singapura tumbuh sebesar $2 \%$, namun pertumbuhan tersebut lebih lambat dibandingkan dengan tahun 2014 yaitu sebesar 3,3\%. Lambatnya pertumbuhan perekonomian Singapura berlanjut sampai tahun 2016, karena 
Produk Domestik Bruto (PDB) Singapura hanya naik 1,8\%. Lambatnya pertumbuhan perekonomian Singapura ini berdampak pada pasar sahamnya yang mengalami penurunan nilai closing price sejak pertengahan bulan Juli 2015 sampai Desember 2016. Tercatat bahwa nilai closing price Singapore Exchange sebesar 50\% yang memiliki nilai dari nilai standar selama 5 tahun terakhir yaitu dari tahun 2012 sampai tahun 2016, sedangkan sisanya sebesar 50\% berada di bawah standar.

\section{Stock Exchange of Thailand}

Pada bursa Stock Exchange of Thailand dapat dijelaskan bahwa nilai closing price yang berada di bawah harga standar yaitu sebesar 46,6\% yang mana nilainya jauh lebih kecil dari nilai closing price yang berada diatas harga standar yaitu sebesar 53,7\%. Hal ini didukung oleh pengaturan belanja negara pemerintah dan kunjungan wisata dari turis asing ke Thailand. Dewan Pembangunan Ekonomi dan Sosial Nasional (NESDB) mencatat bahwa ekonomi Thailand tumbuh sebesar $3,2 \%$ pada tahun 2014, sementara itu, pertumbuhan pada basis tahunan kuartal-ke-kuartal yang disesuaikan secara musiman, ekonomi Thailand mengalami pertumbuhan sebesar $0,6 \%$ pada kuartal III, turun dari pertumbuhan sebesar $0,7 \%$ pada kuartal sebelumnya. Nilai closing price Stock Exchange of Thailand dapat terus menguat karena pada sektor pariwisata di Thailand menagalami kenaikan setiap tahunnya sehingga mempengaruhi kenaikan nilai saham Thailand.

\section{Hanoi Securities Trading Center}

Pada bursa ini dapat dijelaskan bahwa Hanoi Securities Trading Center memiliki nilai closing price yang dibawah standar sebesar 55\%, sedangkan nilai yang berada diatas nilai standar hanya sebesar 45\% dari 5 tahun periode penelitian. Pada tahun 2015, ekonomi Vietnam tumbuh dalam laju tercepat sejak tahun 2007 dan menjaga momentum pertumbuhan sejak 2012. Namun pada Juli 2015 sampai akhir tahun 2016 nilai closing price Vietnam mengalami penurunan dikarenakan beberapa faktor seperti cuaca yang kurang bersahabat sehingga mempengaruhi hasil pertanian Vietnam, bencana lingkungan kelautan sehingga mempengaruhi hasil perikanan Vietnam dan juga faktor ekonomi global yang kurang menguntungkan, yang mengakiatkan posisi pertumbuhan Vietnam berada di belakang India, China dan Filippina.

\section{The Philippines Stock Exchange}

Pada bursa The Philippines Stock Exchange dapat dijelaskan bahwa nilai closing price yang berada di bawah harga standar hanya sebesar 33,37\% sedangkan nilai yang berada di atas standar sebesar $66,67 \%$. Hal ini menunjukan bahwa dari segi nilai bursa saham The Philippines Stock Exchange memiliki nilai yang tertinggi dibandingkan dengan 6 negara lain di kawasan regional ASEAN. Otoritas Statistik Filippina mengumumkan bahwa produk domestik bruto (PDB) Filippina meningkat sebesar 7,1\%. PDB Filippina juga naik 1,2\% dibandingkan kuartal 
sebelumnya. Selain itu faktor politik Filippina juga sangat mempengaruhi perekonomian Filippina, seperti kebijakan - kebijakan yang dibuat oleh Presiden Filippina yang membuat perekonomian naik lebih dari 6\% yang diperkirakan hingga tahun 2018. Pertumbuhan PDB Filippina pada kuartal III 2016 sebesar 7,1\% melampaui China yang sebesar 6,7\% dan Vietnam 6,4\%. Sementara India pada kuartal III 2016 pertumbuhannya mencapai 7,1\% namun belum di publikasikan oleh pemerintah India. Nilai closing price Filiipina dapat menjadi yang terkuat di ASEAN berkat adanya bonus demografi atau pertumbuhan penduduk muda dan dana USD 160 miliar untuk pembangunan infrastruktur untuk menciptakan lapangan kerja baru di Filippina.

\section{Analisis Run Test}

Tabel 4. Hasil Pengujian Run Test

\begin{tabular}{lcccccc}
\hline & BEI & KLCI & SGX & PSEi & SET & VN \\
\hline $\begin{array}{l}\text { Test Value } \\
\text { Asymp. Sig. (2- } \\
\text { tailed) }\end{array}$ & .000 & .000 & .000 & .000 & .000 & .000 \\
\hline
\end{tabular}

Sumber: diolah dari berbagai sumber

Pada uji run test mempunyai hasil dapat dikatakan baik atau memiliki tingkat efisiensi tinggi pada pasar saham apabila memiliki nilai asymp. Sig < dari nilai signifikasinya $(\alpha)$ yaitu sebesar 0,05. Dari tabel diatas dapat dijelaskan mengenai tingkat efisiensi pasar yang terdapat pada 6 pasar saham yang diambil dari negara yang yang memiliki dan aktif di pasar saham pada kawasan regional ASEAN. Mayoritas pasar saham di kawasan regional ASEAN memiliki tingkat efisien yang cukup tinggi hal tersebut didukung oleh adanya perbaikan kinerja pada masing masing bursa saham.

Pada Bursa Efek Indonesia memiliki efisiensi tinggi di karenakan Indonesia telah mengadopsi kebijakan - kebijakan yang telah dilakukan oleh negara - negara yang menjadi financial center seperti Singapura, China, Rusia, dan Amerika Serikat, kebijakan tersebut salah satunya adalah Pusat Informasi Go Publik sehingga memudahkan masyarakat yang ingin menanamkan dana pada bursa efek dapat menempatkan proporsi saham yang tepat. Dengan adanya kebijakan tersebut Bursa Efek Indonesia dapat menarik minat investor lebih banyak dibandingkan pada saat belum menggunakan kebijakan - kebijakan tersebut.

Pada Singapore Exchange memiliki tingkat efisien yang cukup tinggi dikarenakan berbagai macam kebijakan yang telah di buat oleh pemerintah Singapura sehingga dapat menarik investor lebih banyak. Pada Singapore Exchange mempunyai keunggulan pada sektor pariwisata dan bidang jasa lainya. Hal itulah yang menyebabkan Singapore Exchange memiliki tingkat efisien yang cukup tinggi.

Untuk Kuala Lumpur Stock Exchange pada tahun 2016 mengembangkan suatu produk efek yang berbasis syariah yang diharapkan dapat menambah serta meningkat minat para investor untuk bisa menanamkan modalnya di Malaysia. Produk efek berbasis syariah tersebut 
merupakan salah langkah yang dilakukan Malaysia agar mendapatkan tempat dan minat dimata para investor, Kuala Lumpur Stock Exchange dalam mengembangkan produk efek berbasis syariah dengan melakukan kerjasama dengan Bursa Efek Indonesia.

Terakhir pada bursa Stock Exchange of Thailand, The Philippines Stock Exchange dan Hanoi Securities Trading Center dapat dikatakan memiliki tingkat efisien yang baik dikarenakan ketiga bursa saham tersebut mempunyai kebijakan - kebijakan yang dapat menarik minat para investor agar menanamkan dana pada bursa masing - masing negara. Salah satu kebijakannya adalah dual listing atau kebijakan dimana setiap investor atau perusahaan boleh menanamkan dan mendaftarkan nama perusahaannya lebih dari satu negara.

\section{Kolmogorof Smirnov Test}

Tabel 5. Hasil Pengujian One-Sample Kolmogorov-Smirnov Test

\begin{tabular}{|c|c|c|c|c|c|c|}
\hline \multicolumn{7}{|c|}{ One-Sample Kolmogorov-Smirnov Test } \\
\hline & BEI & KLCI & SGX & PSEi & SET & $\mathrm{VN}$ \\
\hline $\mathrm{N}$ & 60 & 60 & 60 & 60 & 60 & 60 \\
\hline Norma Mean & $63,067,026.383$ & $7,348.629$ & 4.350 & $331,795.043$ & $48,040.952$ & $6,692,598.000$ \\
\hline 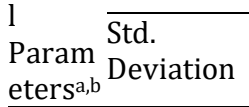 & $59,667,412.016$ & $4,135.029$ & 2.9854 & $431,047.4086$ & $44,387.309$ & $6,199,272.259$ \\
\hline $\begin{array}{l}\text { Asymp. Sig. (2- } \\
\text { tailed) }\end{array}$ & ,200c,d &, $004^{c}$ &, $056^{c}$ &, $017 \mathrm{c}$ & ,200c,d & ,200c,d \\
\hline
\end{tabular}

Sumber: diolah dari berbagai sumber

Pada uji one-sample Kolmogorov-Smirnov Test dapat di nilai memiliki tingkat distribusi nilai closing price yang normal apabila asymp. Sig bernilai > dari nilai signifikasi $(\alpha)$ yaitu sebesar 0,05. Dari tabel diatas dapat dijelaskan mengenai tingkat fluktuasi atau distribusi nilai closing price saham pada 6 pasar saham yang dimiliki dan aktif di negara yang berada di kawasan regional ASEAN. Berikut merupakan penjelasan atas analisis One-Sample Kolmogrov Smirnov Test:

\section{Bursa Efek Indonesia}

Pada Bursa Efek Indonesia dapat dijelaskan bahwa nilai closing price terjadi distribusi secara normal selama 5 tahun periode pengamatan. Tercatat bahwa nilai closing price Bursa Efek Indonesia mengalami kenaikan dari tahun 2012 sampai tahun 2016. Dan fluktuasi nilai sahamnya terbilang normal dikarenakan tidak ada perubahan nilai yang ekstrim atau perubahan nilai saham dibawah $1 \%$ dari satu periode dengan periode waktu lain.

\section{Kuala Lumpur Stock Exchange}

Pada bursa saham ini dijelaskan bahwa terjadi fluktuasi atau distribusi yang tidak normal dari satu waktu ke waktu lain. Hal tersebut terlihat pada harga closing price saham yang mengalami perubahan secara ekstrim yaitu terjadi kenaikan atau penurunan rata - rata sebesar 2\%. Sejak tahun 2012 Kuala Lumpur Stock Exchange mengalami kenaikan nilai closing price 
Analisis Efficient Market Hypotesis Pada Bursa Efek Indonesia ...

sampai bulan Juli tahun 2015 tetapi pada bulan Agustus tahun 2015 mengalami penurunan nilai saham.

\section{Singapore Exchange}

Pada Singapore Exchange dapat dijelaskan bahwa nilai closing price sahamnya mengalami ditribusi nilai saham cukup normal atau perubahan nilai saham dibawah $1 \%$. Hal tersebut terlihat dari nilai closing price sahamnya yang mengalami perubahan secara normal. Pada tahun 2012 sampai bulan Juni tahun 2015 terjadi kenaikan nilai saham, tetapi pada bulan Juli tahun 2015 terjadi penurunan nilai saham sampai akhir tahun 2016. Meskipun terjadi kenaikan dan penurunan nilai saham terjadi secara normal dan tidak ekstrim.

\section{Stock Exchange of Thailand}

Pada bursa Stock Exchange of Thailand dapat dijelaskan bahwa memiliki nilai closing price yang berfluktuasi dengan normal atau distribusi nilai yang normal atau perubahan nilai saham dibawah 1\%, hal itu terlihat pada nilai closing price yang mengalami perubahan setiap tahunnya pada pertengahan tahun antara bulan Juni dan Juli dari tahun 2012 sampai tahun 2016. Perubahan yang terjadi dinilai tidak ekstrim dan masih normal selama 5 tahun terakhir sejak 2012 sampai 2016.

\section{Hanoi Securities Trading Center}

Pada Hanoi Securities Trading Center tidak terjadi fluktuasi nilai closing price secara ekstrim karena perubahan nilai saham sejak tahun 2012 sampai 2016 dapat dikategorikan sebagai perubahan yang normal atau perubahan nilai saham dibawah 1\%. Pada tahun 2012 sampai bulan Mei 2013 mengalami kenaikan harga saham secara normal namun pada bulan Juni 2013 sampai Desember 2013 terjadi penurunan harga saham secara normal. Pada tahun 2014 terjadi kenaikan harga saham, kemudian pada awal tahun 2015 terjadi fluktuasi harga saham secara normal sampai akhir Desember tahun 2016.

\section{The Philippines Stock Exchange}

Pada The Philippines Stock Exchange mengalami fluktuasi nilai closing price secara tidak normal karena perubahan nilai saham tersebut terjadi sangat ekstrim dan mempunyai gap antara nilai saham sebelumnya dengan nilai saham sekarang cukup besar. Sejak tahun 2012 sampai Juli 2013 terjadi kenaikan harga saham namun pada bulan Agustus tahun 2013 terjadi penurunan nilai saham yang cukup ekstrim yaitu sebesar 8,45\% dan hal tersebut terjadi berulang - ulang pada periode Agustus 2013 sampai 1 Desember 2016. 


\section{Pembahasan}

\section{Peringkat Efisien Pasar Saham Bursa Efek Indonesia pada Pasar Saham ASEAN}

Pada hasil analisis dari uji beda dapat dijelaskan bahwa Bursa Efek Indonesia memiliki peringkat efisien pasar pada posisi kedua dibawah dari The Philippines Stock Exchange. Bursa Efek Indonesia memiliki kondisi harga saham yang cukup kuat dikarenakan memiliki nilai closing price yang berada di atas harga standar berjumlah $56,67 \%$ sedangkan nilai yang berada dibawah harga closing price sebesar 43,33\% dari 60 sampel selama 5 periode yaitu tahun 2012 2017. Selama 5 tahun periode pengamatan dapat dijelaskan bahwa nilai closing price terendah terjadi sepanjang tahun 2012, hal itu disebabkan krisis global dunia yang mempengaruhi kondisi ekonomi di Indonesia sehingga Indonesia harus menjaga perekonomian pada sektor riil dan juga memperbaiki volume ekspor Indonesia yang cenderung menurun pada tahun sebelumnya. Selain itu pertumbuhan ekonomi di Indonesia pada tahun 2012 mengalami kenaikan sebesar $6,2 \%$ dengan inflasi yang terkendali sebesar 4,3\%. Pada Bursa Efek Indonesia memiliki efisiensi tinggi di karenakan Indonesia telah mengadopsi kebijakan - kebijakan yang telah dilakukan oleh negara - negara yang menjadi financial center seperti Singapura, China, Rusia, dan Amerika Serikat, kebijakan tersebut salah satunya adalah Pusat Informasi Go Publik sehingga memudahkan masyarakat yang ingin menanamkan dana pada bursa efek dapat menempatkan proporsi saham yang tepat. Dengan adanya kebijakan tersebut Bursa Efek Indonesia dapat menarik minat investor lebih banyak dibandingkan pada saat belum menggunakan kebijakan kebijakan tersebut. Hal ini sesuai dengan penelitian terdahulu oleh Singh, Leepsa, Kushwaha (2016).

\section{Pengaruh Bursa Saham ASEAN terhadap Bursa Efek Indonesia}

Pada bursa saham ASEAN memiliki pengaruh terhadap Bursa Efek Indonesia ketika memiliki efisiensi tinggi secara otomatis akan mempengaruhi tingkat efisien pasar di bursa saham kawasan regional ASEAN. Bursa saham ASEAN memiliki tingkat efisien pasar dengan mayoritas cukup baik yang dibuktikan dengan menguat perekonomian di ASEAN. Selain itu terjadinya kerjasama antara sesama negara ASEAN memungkinkan terjadinya perubahan yang cukup signifikan terutama bagi Bursa Efek Indonesia.

Untuk Kuala Lumpur Stock Exchange pada tahun 2016 mengembangkan suatu produk efek yang berbasis syariah yang diharapkan dapat menambah serta meningkat minat para investor untuk bisa menanamkan modalnya di Malaysia. Produk efek berbasis syariah tersebut merupakan salah langkah yang dilakukan Malaysia agar mendapatkan tempat dan minat dimata para investor, Kuala Lumpur Stock Exchange dalam mengembangkan produk efek berbasis syariah dengan melakukan kerjasama dengan Bursa Efek Indonesia. Hal ini sesuai dengan penelitian terdahulu oleh Nassar (2016). 


\section{Bursa Efek Indonesia memiliki Kategori Efisien Pasar Pada Pasar Saham ASEAN}

Pada bursa saham ASEAN mayoritas masing - masing negara memiliki kategori untuk bisa menjadi pasar yang efisien. Hal ini dibuktikan dengan Bursa Efek Indonesia memiliki efisiensi tinggi karena Indonesia telah mengadopsi kebijakan - kebijakan yang telah dilakukan oleh negara - negara yang menjadi financial center seperti Singapura, China, Rusia, dan Amerika Serikat, kebijakan tersebut salah satunya adalah Pusat Informasi Go Publik sehingga memudahkan masyarakat yang ingin menanamkan dana pada bursa efek dapat menempatkan proporsi saham yang tepat. Dengan adanya kebijakan tersebut Bursa Efek Indonesia dapat menarik minat investor lebih banyak dibandingkan pada saat belum menggunakan kebijakan kebijakan tersebut.

Bursa Efek Indonesia memiliki nilai closing price terdistirbusi secara normal selama 5 tahun periode pengamatan. Tercatat bahwa nilai closing price Bursa Efek Indonesia mengalami kenaikan dari tahun 2012 sampai tahun 2016. Dan fluktuasi nilai sahamnya terbilang normal dikarenakan tidak ada perubahan nilai yang ektrim atau perubahan nilai saham dibawah $1 \%$ dari satu periode dengan periode waktu lain. Hal ini sesuai dengan penelitian terdahulu oleh Stakic, Jovancai, Kapor (2015).

\section{Pasar Saham ASEAN Memiliki Pola Return Saham Random terhadap Pasar Saham di Masing - masing negara di ASEAN}

Pada Bursa Efek Indonesia dapat dijelaskan bahwa nilai closing price terjadi distribusi secara normal selama 5 tahun periode pengamatan. Tercatat bahwa nilai closing price Bursa Efek Indonesia mengalami kenaikan dari tahun 2012 sampai tahun 2016. Sedangkan fluktuasi nilai sahamnya terbilang normal dikarenakan tidak ada perubahan nilai yang ekstrim atau perubahan nilai saham dibawah $1 \%$ dari satu periode dengan periode waktu lain.

\section{KESIMPULAN}

Berdasarkan hasil analisis data dan pembahasan dapat ditarik kesimpulan bahwa: (1) Bursa Efek Indonesia menempati peringkat efisien market di posisi kedua setelah The Philippines Stock Exchange hal tersebut dikarenakan Bursa Efek Indonesia memiliki nilai harga saham yang berada di atas harga standar jauh lebih sedikit dibandingkan dengan The Philippines Stock Exchange; (2) Bursa saham ASEAN memiliki pengaruh terhadap Bursa Efek Indonesia hal tersebut terbukti dalam tingkat efisiensi pasar saham ASEAN mayoritas memiliki tingkat efisien yang baik, namun yang membedakan adalah kondisi closing price saham setiap negara yang mempunyai fluktuasi berbeda - beda tergantung dari kondisi internal suatu negara. Saat terjadi perubahan maka kondisi tersebut akan berdampak terhadap nilai pasar saham di kawasan regional ASEAN.; (3) Bursa Efek Indonesia memiliki kategori dapat menjadi pasar saham yang 
efisien dikawasan ASEAN, hal itu terbukti dengan adanya kebijakan - kebijakan yang telah dibuat pemerintah seperti Pusat Informasi Go Publik dengan tujuan untuk bisa menarik minat investor agar menanamkan dananya di Bursa Efek Indonesia; dan (4) Bursa Efek Indonesia memiliki pola return yang berfluktuasi secara normal, dapat dikatakan normal karena pada perubahan closing price terjadi tidak terlalu ekstrim yaitu dibawah dari $1 \%$.

\section{DAFTAR PUSTAKA}

Aumeboonsuke, V. 2013. Weak Form Efficiency of Six Equity Exchange in ASEAN. Europan Journal of Scientific Research, 532 - 538.

Dyakova, A., dan Smith, G. 2014. African Stock Markets: Efficiency And Relative Predictability. South African Journal of Economics, 1 - 18.

Gupta, R., dan Guidi, F. 2013. Market Efficiency in the ASEAN Region: Evidence Form Multivariate and Cointegration. Applie Financial Economics, 37 - 41.

Yuan, T., dan Gupta, R. 2014. Chinese Lunar Year Effect in ASIAN Stock Market, 1999 - 2012. Departement of Accounting Finance and Economic Griffith University, Australia, 1-9.

Stakic, N., Kapor, P., dan Jovancai, A. 2015. The Efficiency of The Stock Market in Serbia. Jounal of Policy Modeling, 1-10.

Singh, R., dan Leepsa, N., Kushwaha, N. N. 2016. Testing the Weak Form of Efficient Market Hypothesis in Carbon Efficient Stock Indices Along with Their Benchmark Indices in Select Countries. Iranian Journal of Management Studies , 627 - 650.

Maheswarant, S., dan Sahik, M. 2016. Random Walk in Emerging ASIAN Stock Markets. International Journal of Economic, 1-12.

Nassar, S. 2016. The Day of The Week Effect of Stock Return Emperical Evidence From Five Selected Arab Countries. Eurasian Journal of Business And Management, 55-64.

Salim, M., Rabbani, S., dan Kamal, N. 2013. Testing the Weak-Form Efficiency of The Stock Market: Pakistan as an Emerging Econoy. Journal of Basic Applied Scientic Research, 136 - 142.

Tandelilin, E. 2010. Portofolio dan Investasi Teori dan Aplikasi. Yogyakarta: Kanisius. 